\title{
Assessment, treatment goals and interventions for oedema/lymphoedema in palliative care.
}

\author{
$\underline{\text { Cobbe S}}, \underline{\text { Real S }}$, Slattery S.
}

\section{Background:}

Lymphoedema and non-lymphatic oedema are common occurrences in palliative care patients, although their true prevalence remains unknown (Real et al 2016). They occur in many advanced diseases including advanced cancer, AIDS, heart failure, advanced kidney disease and respiratory failure. The causes are numerous and include blockage of lymphatics by tumours, lymphadenopathy, hypoalbuminaemia, venous hypertension (fluid overload or retention), immobility, venous thrombosis and drugs (ILF\&CLF 2010). Lymphoedema in this population adversely affects physical and social functioning, has a negative impact on body image and contributes to feelings of fear and loss of control (Frid et al 2006). In the general population, oedema and lymphoedema are a known risk factor for cellulitis (Mc Gilvray 2013; Riches and Keeley 2012, ILF 2012) and treatment has shown reductions in hospitalisations due to cellulitis (Morgan and Guckin 2013; Arsenault et al 2011). The recommended approach for palliative care oedema/lymphoedema is firstly medical assessment and treatment for reversibility of any contributing factors (ILF\&CLF 2010). These might include radiotherapy to reduce tumour size, paracenthesis to remove ascites, medical treatment of venous hypertension including diuretics, and treatment of anaemia. Thereafter oedema is managed using an adapted version of complex/complete decongestive therapy [CDT] (ILF \& CLF 2010; Towers et al 2010, Cooper 2012; Honnor 2008).This involves manual lymphatic drainage (massage), compression bandaging/garments, skin care education and exercise, depending on the type of oedema.

In non-palliative patients, CDT has consistently been found effective at reducing limb volume in patients with lymphoedema (Finnane et al 2015, Leung et al 2015), and a similar approach, with the exclusion of lymphatic massage, is used to reduce volume in non-lymphatic oedema (Cooper 2013; Todd 2013). There is, however, limited evidence to support the use of physical interventions, including CDT, for lymphoedema in palliative care populations (Beck et al 2013), and no substantial evidence for physical treatments of non-lymphatic oedema. This is mainly due to lack of research. Anecdotal reports record benefits for palliative care patients, which include volume reduction, relief of symptoms, maintenance of function, better social functioning and improved skin quality (Cooper 2012, Williams 2004).

This lack of studies into the care of palliative care oedema means that there is little to guide the assessment and management of oedema in palliative care patients. Both lymphoedema and nonlymphatic oedema occur in this population, as well as a mixed oedema type (Real et al 2016). Lower limb oedema is the most common site (Real et al 2016, Thompson and Walker 2011). In addition, treatment goals may differ from other oedema population as volume reduction may not always be a realistic aim. This is the case when there is complete obstruction of lymphatics by disease, also in advanced disease when non-reversible organ failure occurs. In such cases, gains in QOL or skin quality may take precedence. As a result, measurements other than limb volume are necessary in order to establish effectiveness of treatments in this patient population.

Apart from two studies, which reported on a lymphoedema service in a palliative care population (Thompson and Walker 2011; Clemens et al 2010), current practice in terms of assessment and treatment of palliative care oedema is unknown. 


\section{Aims of Study:}

This study aims to establish current practice for the treatment of oedema in palliative care patients in an Irish specialist palliative care service, in order to identify further research needs and challenges in this field. Milford Care Centre is the service provider of specialist palliative care services in the Mid-West region of Ireland. The oedema service comprises one full-time post, shared amongst 4 physiotherapists.

Specific objectives were to determine the following:

- The methods used for assessment of oedema

- The treatments being used for management of oedema

- The duration of treatment and reasons for discharge

- Treatment aims

This is the first known study of its type.

\section{Methods:}

This is a secondary analysis of a service evaluation previously reported (Real et al 2016).

A retrospective chart review was conducted on the physiotherapy charts of patients who were assessed by the specialised oedema service in Milford Care Centre, between August 2013 and January 2014. All new cases referred to the oedema service were included and patient characteristics have been reported previously (Real et al 2016).

Formation of data collection tool and categorisation of oedema types:

Prior to commencement of study, a data collection tool (Appendix 1) was devised following a round-table discussion amongst 4 senior physiotherapists, all from Milford Care Centre, who are trained lymphoedema therapists. Each had between 5-11 years of specialist experience in the treatment of palliative care oedema. All coding pre-and post-study was conducted by this panel, guided by available literature and clinical experience. For this paper, the following prestudy decisions are relevant (Appendix 1):

- 6 possible assessment methods/variables were described

- 8 interventions for oedema were described

- 8 aims of treatment were outlined

Data Extraction:

Treating physiotherapists filled out the data collection tool as each patient was discharged, using information from the medical and physiotherapy charts. 
Post-study coding: Duration of treatment was divided into time periods of weeks and months.

Data Analysis:

Data was transferred by the primary researcher to an Excel spreadsheet and analysed using Microsoft Excel.

\section{Ethical Considerations:}

Ethics approval was sought and received from Mid-Western Regional Ethics Committee in June 2013.

\section{Results}

During the 6 month period, 64 cases were referred to the oedema service, involving 61 individuals. 1 patient was excluded, as they had no oedema and were referred preventatively for advice/education. The population referred is reported in Table 1. The occurrence of lymphoedema (29\%), non-lymphatic oedema (16\%), mixed oedema (46\%) and lymphorrhoea (16\%) was reported. Further details have previously been published (Real et al 2016). 92\% had a cancer diagnosis. 39 (61\%) were treated at home, 14 (22\%) as inpatients, the remainder as out-patients or in more than one setting. Treatment duration lasted from 1-176 days (median 7).

\section{Assessment and goals:}

Patients were assessed using a number of different methods, more than one being used for most patients. The most common method of assessment was circumferential measurements (78\%), followed by skin descriptors (73\%) and function (72\%) using EFAT-2 (Kaasa and Wessel 2001). See Figure 1.

The treatment goals are outlined in Figure 2: for most patients, more than one goal was identified. Goals were a mixture of maintenance and improvement. The most common goals were to maintain skin integrity (54\%), to reduce limb volume (51\%) and to improve QOL (48\%).

\section{Interventions used:}

All patients received at least one intervention, most received more than one type. All received education about their oedema. Compression garments $(57.7 \%)$ and multi-layer bandaging $(50 \%)$ were the most commonly used physical treatments. Manual lymphatic drainage (MLD) and K-taping were only used on those with a lymphoedema component to their oedema (See Table 2). Closed subcutaneous drainage, as described by Clein and Pugachev (2004), was not used during the study period, despite being an available option by our medical team.

Treatment duration ranged from 1-176 days, being shortest for those with a mixed oedema type (See Table 3). The average number of treatments was 3.5, and was highest for those with lymphoedema. 
The main reasons for ceasing oedema treatment were due to death and clinical deterioration. 19\% were discharged because their oedema had stabilised and no longer required professional input.

$75 \%$ of oedema patients also received other physiotherapy treatments( e.g. mobility, breathlessness, pain interventions) while being treated for oedema.

\section{Discussion:}

\section{Assessment and Tools:}

The most common assessment tool used was circumferential measurements (78\%). They are easy to use, have good reliability (Taylor 2006) and remain the first choice recommendation for lymphoedema practitioners (Perdemo et al 2014; ILF 2006). Skin descriptors [i.e. description of skin colour, texture and surface by the clinician] were the next most commonly-used measurement (73\%). The detrimental effects of oedema on skin quality and function are well described in the literature (Flour 2013; Nowicki and Siviour 2013; ILF 2012) however, to date, there is no standard measurement for the observed effects of oedema on skin. This proves an enormous challenge to research in this field. Photographs, used in $5 \%$ of cases, are very useful clinically and in case studies for observing changes in skin appearance and limb volume/shape, but it is difficult to quantify and analyse the information contained therein for research purposes.

Functional measures, both EFAT-2 (Kaasa and Wessel, 2001 (72\%) and other descriptions of function (43\%)[ ability to walk, transfer, level of assistance required] were used to measure impact of oedema on function. The authors suggest that oedema-specific functional tools may be required to fully capture the effect of treatments on function in this patient population, such as the physical domains of lymphoedema QOL tools.

QOL tools were rarely used (13\%) by the service, mainly due to lack of a suitable tool for palliative care patients. At the time of study, just one QOL tool was available for both leg and arm, the LYMQOL (Keeley et al. 2010). Our service found it to be suitable for a small proportion of highly functioning patients, but too complicated and burdensome for many. Newer tools, such as Lymph-ICF-LL (Devoogdt et al 2014) are relatively lengthy. The development of a short oedema-specific QOL tool for palliative care patients is imperative for quality research to occur in this patient population.

\section{Aims of Treatment:}

Unlike the general oedema population, where volume reduction is most frequently the goal, the most salient difference in our palliative care population was that other treatment effects were commonly the goal, and that maintenance (i.e. preventing deterioration) was often the primary treatment aim. As the International Lymphoedema Framework (ILF 2012) stated, outcomes of comfort and function may be more important in palliative care patients.

Maintaining skin function was the most common goal of treatment (53\%) and improving skin was the goal for $36 \%$. This indicates the importance of skin issues in this patient population, once again highlighting the lack of a suitable assessment tool for this purpose.

Reducing volume was the goal for just half the patients (50\%) and maintaining volume was the goal for $34 \%$. This pointedly reflects the pragmatism of treating palliative care patients with oedema/lymphoedema, for whom a decrease in volume may not be realistic or possible. 
Improving function was a goal in $36 \%$ of patients. Clinically, it is observed that walking and bed transfers become more difficult when lower limbs are swollen, and that feeding and personal care become difficult with upper limb oedema. Improving these functional tasks is therefore a reasonable goal of treatment.

Improving QOL was the goal in almost half the patients (47\%). QOL in palliative care patients is linked with physical and social functioning, subjective appraisal of symptoms and wellbeing (Kaasa and Loge 2003). Most of the oedema literature alludes to the emotional effect of having oedema, but only one paper was found specifically dealing with the subject (Creedon 2011): Oedema results in disfigurement causing distress, body image and relationship issues; clothing becomes difficult to buy and wear; functional tasks become more difficult which may lead to reduced activity and participation; and there is also a sense of loss of control. In addition, in advanced disease lymphoedema also made patients fearful of the future (Frid et al 2006), as it depicted change and possible decline. Anecdotally, palliative care patients report better wellbeing and functioning after oedema treatments (Cobbe et al 2016) but there is no research to date, which examines these findings in greater detail.

Reduction in pain was an aim for $14 \%(n=9)$ of patients. Pain due to oedema/lymphoedema itself is not well described in the literature, although one non-palliative cohort of lymphoedema patients reported an incidence of $60 \%$ when specifically asked (Ryan et al 2003). Patients may describe altered sensations, such as heaviness, tightness or tenderness (Frid et al 2006, Ryan et al 2003). Clemens et al (2010) showed a clinical reduction in oedema-related pain in palliative care patients after manual lymphatic massage. It is possible that the pain-reducing effect of treatment is underestimated by clinicians, and therefore infrequently measured.

Improving balance was cited as an aim in $13 \%(n=8)$ of patients. Although this is not reported in the literature, clinicians have found that unilateral swelling or ascites can significantly alter a patient's base of support and affect both static and dynamic balance. In our service, treatments have been found to mitigate this.

\section{Interventions used:}

All patients treated received education as part of their treatment [causes of swelling, skincare management, precautions, footwear advice, self-management techniques]. This compares with $95 \%$ for a similar PC service (Thompson and Walker 2011). Education is seen as an intrinsic part of oedema care (ILF \& CLF 2010, Todd 2013b), encouraging self-management of the condition. External compression [compression garments (59\%), bandaging (51\%)] was the most commonly used physical treatment for all oedema types. Bandaging reduces limb volume and improves limb -shape, however long-term management is achieved through compression garments (Cooper2015, Cooper 2013). Bandaging is known to reduce or stop fluid leakage from the skin (Jones 2011; Delon 2012), therefore all of our patients with lymphorrhoea were bandaged.

Only those with a lymphatic component received lymphatic massage and kinesiotaping. Lymphatic massage involves strategic massage of lymph nodes to improve their functioning, complemented with superficial massage along skin, which directs lymphatic fluid to the nearest functioning deep lymphatics. It is not used for non-lymphatic oedema (Todd 2013). Some authors have suggested that part of its therapeutic value may be through the power of touch on ill and frail patients (Towers et al 2010; ILF \&CLF 2010). Kinesiotaping taping was also only used for patients with lymphoedema. K-tape is elasticated tape, applied strategically to areas where superficial lymphatic flow is affected. When the patient moves the affected area, the tape stretches in a multidirectional fashion. This is believed to stimulate the superficial lymphatics. It can only be used on good quality skin and is considered to be of use in areas of localised swelling (Thompson and Walker 2011). There is much anecdotal evidence for its use, but research is lacking (Wigg and Lee 2013).

Exercise and deep breathing were used as interventions in $38 \%$ and $34 \%$ of patients respectively. Both are seen as adjuncts to oedema management by assisting lymphatic flow and increasing the efficiency of anatomical pumps (ILF \& CLF 2010) but their effectiveness has yet to be estabished. 
Treatment duration and number of treatments:

Treatment duration (see Table 3) shows that interventions for oedema are typically of short duration: $28 \%$ were seen for 1 visit only and 52\% were seen for less than 1 week. There was, however, a cohort of patients who received numerous treatments over a prolonged length of time, indicating that some palliative care patients have longer-term oedema issues, which may respond to physical treatments. Regarding discharge from the service, the most common reasons were due to death $(37 \%)$ or clinical deterioration (21\%). This highlights the unstable population of patients being treated for oedema, many nearing end of life. Conversely, $19 \%$ of patients were stable and discharged because their oedema was controlled and being self-managed.

The authors suggest that at least 3 possible cohorts of patients are being seen by the service: 1 ) those for whom a short episode of advice is required, followed by self-maintenance; 2 ) those for whom oedema is a harbinger for terminal decline - these require supportive measures and treatment is of short duration; 3 ) those for whom a longer period of treatment is required, followed by a maintenance period or decline. This latter cohort may be most likely to show the benefits of oedema interventions and needs to be investigated.

Three in every 4 patients also received other physiotherapy interventions, once referred to the oedema service. This suggests that an oedema service fits in well as part of a palliative care physiotherapy service, as other physical needs can be assessed at the time of referral. In addition, most of the patients were treated at home or as outpatients: oedema often occurs when the patient is free of other major symptoms, and in our service only infrequently requires an inpatient admission for treatment.

\section{Conclusion}

Oedema treatments for palliative care patients are adapted from traditional CDT methods used for treating lymphoedema and oedema in the general population. This study assessed the treatment goals, assessment methods and treatments used for a cohort of palliative care patients with oedema. Different interventions were used for different oedema types. Education (100\%), compression garments (59\%) and bandaging (51\%) were the most commonly used interventions. The goals of treatment focussed on maintaining or improving skin quality, function and QOL rather than merely the reduction of limb volume. Treatment was typically of short duration, but there was a cohort of patients who required prolonged oedema treatment. The assessment of oedema for research purposes is hampered by lack of tools to measure skin quality and oedema-related QOL in palliative care patients. Research is required to measure the effectiveness of CDT in palliative care patients and to identify patient cohorts who benefit from this treatment approach.

\section{Conflicts of interest:}

None

\section{References:}


Arsenault,K., Rielly, L. and Wise, H. (2011) 'Effects of complete decongestive therapy on the incidence of hospitalisation for the management of recurrent cellulitis in adults with lymphedema', Rehabilitation Oncology, 29(3): 14-

Beck, M., Wanchai, A., Stewart, B., Cormier, J. and Armer, J. (2012) 'Palliative care for cancer-related lymphedema: A systematic Review', Journal of Palliative Medicine, 15(7): 821-8.

Clein., L and Pugachev, E, (2004) 'Reduction of edema of lower extremities by subcutaneous, controlled drainage: Eight cases', Am J Hosp Palliat Care, 21: 228-32

Clemens, K., Jaspers, B., Klaschick, E and Nieland, P. (2010) 'Evaluation of the clinical effectiveness of physiotherapeutic management of lymphoedema in palliative care patients', Japanese Journal of Clinical Oncology, 40(10): 1068-1072

Cobbe, S., Nugent, K and Real, S (2016) 'The Effectiveness of Complex Decongestive Physiotherapy for Lymphoedema in Advanced Cancer Patients', in Abstracts of the 9th World Research Congress of the European Association for Palliative Care (EAPC), Palliat Med June 2016 vol. 30 no. 6, NP83

Cooper, G (2015) 'Compression therapy and the management of lower limb lymphoedema: the male perspective', British Journal of Community Nursing, 20(3): 118-124.

Cooper, G (2013) 'Compression Therapy in chronic oedema and lymhoedema', Nursing and Residential care, 15(3): 134-9

Cooper, G (2012) 'Lymphoedema treatment in palliative care: a case study', British Journal of Nursing, 21(15): 897-903

Creedon, R (2011) 'The psychological effects of living with chronic oedema', Chronic Oedema, Apr S14-19.

Delon, M (2012) 'A new model of care for 'leaking legs', Chronic Oedema, Oct: S12-18

De Voogdt, N., De Groed, A., Hendrickx, A., Damstra, R., Christiaansen, A., et al (2014)' Lymphoedema Functioning, Disability and health Questionnaire for lower limb lymphoedema (Lymph-ICF-LL): Reliability and Validity', Physical Therapy, 94(5): 705-721

Finnane, A., Minika, J.and Hayes, S. (2015) 'Review of the evidence of lymphedema treatment effect', American Journal of Physical Medicine and Rehabilitation, 94(6): 483-498

Flour, M. (2013) 'Dermatological Issues in lymphoedema and chronic oedema', Journal of Community Nursing, 27(2): 27-32.

Frid, M., Strang, P., Friedrichsen, M. and Johansson, K. (2006) 'Lower limb Lymphedema: Experience and perceptions of cancer in the late palliative stage, Journal of Palliative Care', 22(1): 5-11

Honnor, A (2008) 'The management of Chronic oedema in palliative care', Chronic Oedema , 14(4): S4-9

ILF, International Lymphoedema Framework( 2006) Best practice for the Management of Lymphoedema. Online at: 
http://www.lympho.org/mod turbolead/upload/file/Lympho/Best practice 20 July.pdf [accessed $\underline{21} \operatorname{Jan} 2016]$

ILF, International Lymphoedema framework (2012) Compression Therapy: A Position Document on Compression Bandaging. Online at:

http://www.lympho.org/mod turbolead/upload//file/Resources/Compression\%20bandaging\%20\%20final.pdf [accessed Jan 212016$]$

ILF \& CLF, International Lymphoedema Framework and Canadian Lymphedema Framework (2010) The management of lymphoedema in advanced cancer and oedema at the end of life. Online at: http://www.lympho.org/mod turbolead/upload/file/Palliative\%20Document\%20-\%20protected.pdf [accessed Jan 21 2016]

Jones, J (2011) 'Non-concordance in lymphorrhoea of the lower limbs: a case study', Chronic oedema, Oct: S14-19

Kaasa, S. and Loge, JH (2003) 'Quality of life in palliative care: principles and practice', Palliative Medicine 2003; 17: 11-20

Kaasa, T. And Wessel, J. (2001) 'The Edmonton functional assessment tool: further development and validation for use in palliative care', Journal of Palliative Care, 17(1), 5-11.

Keeley, V., Crooks, S., Locke, J., Veigas, D., Riches, K and Hilliam, R. (2010) 'A quality of life measure for limb lymphoedema', Journal of Lymphoedema, 5(1): 26-37

Leung, E., Tirlapur, S. and Meads, C. (2015) 'The management of secondary lower limb lymphoedema in cancer patients: A systematic review', Palliative Medicine, 29(2): 112-119

Mc Gilvray, (2013) 'Lymphoedema and cellulitis: a narrative review', Wound Practice and Research', 21(2):56-60

Morgan,K and Guckin, J(2013) 'Reducing cellulitis and improving skin integrity through lymphoedema and dermatology collaboration', Chronic oedema, Oct 2013, S13-17

Novicki, J. and Siviour, A (2013) 'Best practice skin care management in lymphoedema', Wound Practice and Research, 21(2): 61-65

Perdemo, M., Davies, C., Levenhagen, K. and Ryans, K. (2014) 'Assessment Measures of Secondary Lymphedema in breast cancer survivors', Rehabilitation Oncology, 32(1): 22-35

Real, S., Cobbe, S. and Slattery, S. (2016) 'Palliative Care Edema: Patient population, causal factors, and types of edema referred to a specialist palliative care edema service', Journal of Palliative Medicine',19 (7):771-7.

Riches, K. and Keeley, V (2012) 'Cellulitis in patients with chronic oedema', Nursing and Residential Care, 14(3): 122-27 
Ryan, M., Stainton, C., Jaconelli, C., Watts, S., Mc Kenzie, P. and Mansberg, T. (2003) 'The experience of lower limb lymphedema for women after treatment for gynecologic cancer', Oncology Nursing Forum, 30(3): 417-23

Taylor, R., Jayasinghe, UW., Koelmeyer, L., Ung, O and Boyages, J. (2006) 'Reliability and validity of Arm Volume measurements for assessment of lymphoedema', Physical Therapy., 86(2): 205-14

Thompson, $\mathrm{M}$ and Walker, J. (2011)' Collaborative lymphoedema management: developing a clinical protocol', Int J Pall Nurs, 17(5): 231-8.

Todd, M. (2013) 'Chronic Oedema: impact and management', British Journal of Nursing, 22(11): 62327

Todd, M (2013b) 'Self-management in chronic oedema', British Journal of Nursing, 22(12): 701-4

Towers, A., Hodgson, P., Shay, C. and Keeley, V. (2010) 'Care of palliative patients with cancerrelated lymphoedema', Journal of Lymphoedema, 5(1): 72-80

Wigg, J. and Lee, N (2013) 'Refining essential care in lymphoedema' Chronic Oedema. April 2014: $\$ 20-27$

Williams, A. (2004) 'Understanding and managing lymphoedema in people with advanced cancer', Journal of Community Nursing, 18(11): 30-40 
Table 1: Demographics of participants

\section{Patient Demographics ( $n=64)$}

\begin{tabular}{|c|c|}
\hline Males & $27(42.2 \%)$ \\
\hline Females & $37(57.8 \%)$ \\
\hline Ages & $\begin{array}{l}\text { Range } 45-97 \\
\text { Median } 72\end{array}$ \\
\hline New Patients referred & 64 \\
\hline Patients continuing treatment & 5 \\
\hline Drop outs before assessment & 5 \\
\hline Number treated & 64 \\
\hline CANCER DIAGNOSIS & $59(92.2 \%)$ \\
\hline Breast & $11(17.2 \%)$ \\
\hline Ovarian/Cervical & 9 (14.1\%) \\
\hline Pancreatic & $9(14.1 \%)$ \\
\hline Lung & $7(10.9 \%)$ \\
\hline Prostate/Penile & $6(9.4 \%)$ \\
\hline Colon/Rectal & $4(6.2 \%)$ \\
\hline Mantle Cell & $3(4.7 \%)$ \\
\hline Skin cancers & $3(4.7 \%)$ \\
\hline Renal & $2(3.2 \%)$ \\
\hline Osteosarcoma & $1(1.6 \%)$ \\
\hline Unknown Primary & $1(1.6 \%)$ \\
\hline Liver & $1(1.6 \%)$ \\
\hline Cholangiosarcoma & $1(1.6 \%)$ \\
\hline NON CANCER DIAGNOSIS & $5(7.8 \%)$ \\
\hline COPD & $2(3.2 \%)$ \\
\hline Cardiac disease & $1(1.6 \%)$ \\
\hline
\end{tabular}


Table 2: Treatments Utilised for Oedema

Table 2: Treatments Utilised for Oedema

\begin{tabular}{|l|l|l|l|l|l|}
\hline & $\begin{array}{l}\text { Lymphoede } \\
\text { ma } \\
(\mathrm{n}=18)\end{array}$ & $\begin{array}{l}\text { Mixed } \\
\text { lymphoedema / } \\
\text { non-lymphatic } \\
\text { oedema (n=29) }\end{array}$ & $\begin{array}{l}\text { Non- } \\
\text { lymphatic } \\
\text { oedema } \\
(\mathrm{n}=10)\end{array}$ & $\begin{array}{l}\text { Lymphorrhoea } \\
(\mathrm{n}=6)\end{array}$ & $\begin{array}{l}\text { Total } \\
(\mathrm{n}=63)\end{array}$ \\
\hline Education & $18(100 \%)$ & $29(100 \%)$ & $10(100 \%)$ & $5(100 \%)$ & $63(100 \%)$ \\
\hline Garments & $13(68.4 \%)$ & $17(58.6 \%)$ & $5(50 \%)$ & $2(33.3 \%)$ & $37(58.7 \%)$ \\
\hline
\end{tabular}




\begin{tabular}{|c|c|c|c|c|c|}
\hline Bandaging & $9(50 \%)$ & $10(34.5 \%)$ & $8(80 \%)$ & $5(100 \%)$ & $32(50.8 \%)$ \\
\hline Exercise & $9 \quad(50 \%)$ & $11(37.9 \%)$ & $4(40 \%)$ & 0 & $24(38.1 \%)$ \\
\hline Deep breathing & $9(50 \%)$ & 8 (27.6\%) & $2(20 \%)$ & $3(50 \%)$ & $22(34.9 \%)$ \\
\hline MLD & 8 (44.4\%) & $13(44.8 \%)$ & 0 & $1(16.7 \%)$ & $22(34.9 \%)$ \\
\hline K-Taping & $5(27.7 \%)$ & $5 \quad(17.2 \%)$ & 0 & 0 & $10(15.9 \%)$ \\
\hline $\begin{array}{l}\text { Subcutaneous } \\
\text { drainage }\end{array}$ & 0 & 0 & 0 & 0 & 0 \\
\hline Other Physiotherapy & $13(72.2 \%)$ & $22(75.9 \%)$ & $8(80 \%)$ & $4(67 \%)$ & 47 (75\%) \\
\hline $\begin{array}{l}\text { Treatment duration } \\
\text { (days) }\end{array}$ & $\begin{array}{l}\text { Range 1-176 } \\
\text { Median } 10.5 \\
\end{array}$ & $\begin{array}{l}\text { Range 1-63 } \\
\text { Median } 2\end{array}$ & $\begin{array}{l}\text { Range 1-120 } \\
\text { Median } 10\end{array}$ & $\begin{array}{l}\text { Range 1-37 } \\
\text { Median 10.5 }\end{array}$ & $\begin{array}{l}\text { Range 1-176 } \\
\text { Median } 7\end{array}$ \\
\hline Number of treatments & $\begin{array}{l}\text { Range 1-14 } \\
\text { Average } 5.1\end{array}$ & $\begin{array}{l}\text { Range 1-11 } \\
\text { Average } 2.79\end{array}$ & $\begin{array}{l}\text { Range 1-8 } \\
\text { Average } 3.1\end{array}$ & $\begin{array}{l}\text { Range 1-7 } \\
\text { Average } 3.5\end{array}$ & $\begin{array}{l}\text { Range 1-14 } \\
\text { Average } 3.5 \\
\text { Mode } 1\end{array}$ \\
\hline $\begin{array}{l}\text { Days to death } \\
\text { (days) }\end{array}$ & $\begin{array}{l}(n=17) \\
\text { Range 5-178 } \\
\text { Median } 26\end{array}$ & $\begin{array}{l}(n=27) \\
\text { Range 1-128 } \\
\text { Median } 14\end{array}$ & $\begin{array}{l}(\mathrm{n}=8) \\
\text { Range 7-225 } \\
\text { Median } 26\end{array}$ & $\begin{array}{l}(n=6) \\
\text { Range 2-190 } \\
\text { Median } 5\end{array}$ & $\begin{array}{l}(n=58) \\
\text { Range 1-225 } \\
\text { Median } 19\end{array}$ \\
\hline $\begin{array}{ll}\text { REASONS } & \text { FOR } \\
\text { DISCHARGE } & \end{array}$ & $(n=18)$ & $(n-29)$ & $(n=10)$ & $(n=6)$ & $(n=63)$ \\
\hline Deceased & 6 & 15 & 1 & 1 & 23 \\
\hline Clinical deterioration & 2 & 5 & 2 & 4 & 13 \\
\hline Stable & 4 & 5 & 3 & 0 & 12 \\
\hline Declined & 0 & 2 & 0 & 0 & 2 \\
\hline $\begin{array}{l}\text { Discharged from } P C \\
\text { service }\end{array}$ & 2 & 1 & 0 & 0 & 3 \\
\hline No longer appropriate & 0 & 0 & 1 & 0 & 1 \\
\hline $\begin{array}{l}\text { Ongoing } \\
\text { after study }\end{array}$ & 4 & 0 & 3 & 1 & 8 \\
\hline
\end{tabular}

Table 3: Treatment Duration

\begin{tabular}{|ll|}
\hline Duration of Treatment \\
\hline One visit & 18 \\
\hline S1 week & 15 \\
\hline 2-3 weeks & 8 \\
\hline 4 - 7 weeks & 7 \\
\hline 8-11 weeks & 7 \\
\hline 12-15 weeks & 0 \\
\hline 16- 19 weeks & 3 \\
\hline 4-12 months & 2 \\
\hline >1 year & 1 \\
\hline & \\
\hline
\end{tabular}

Fig 1: Measurement of oedema 


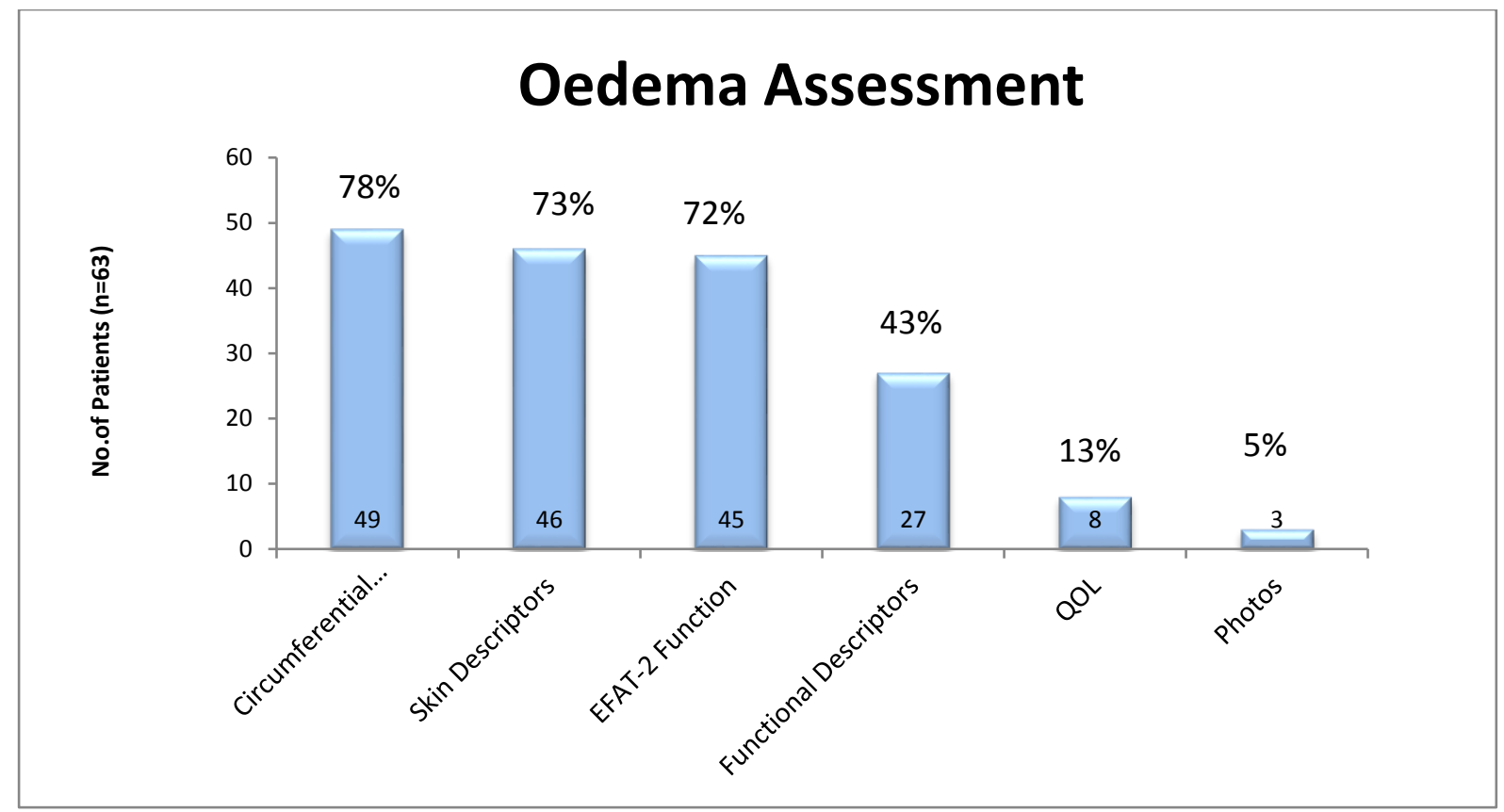

Fig 2: Goals of Treatment

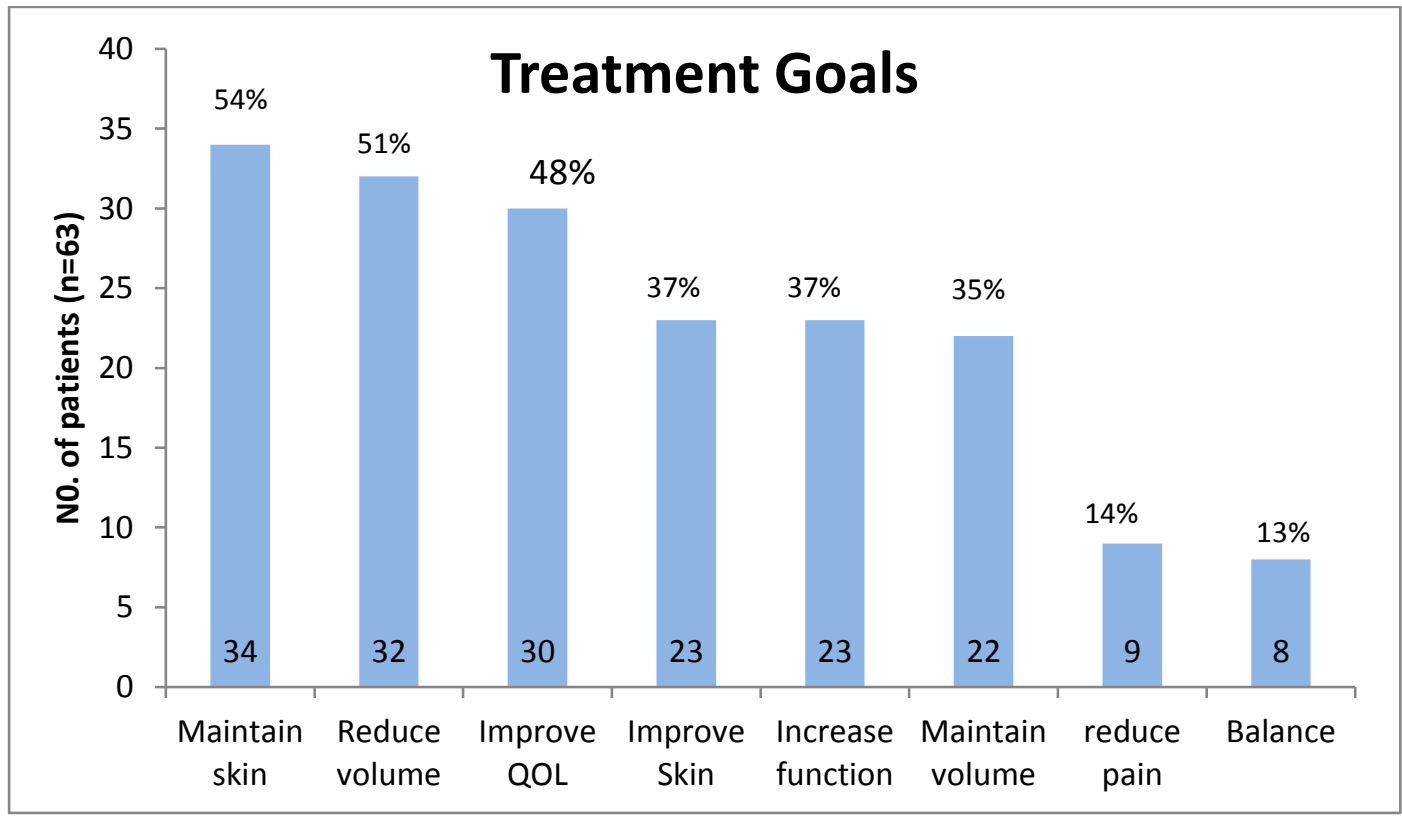


